\title{
The Effect of Selected Feed Mixtures on the Duodenal Morphology: Comparison Study
}

\section{P. MAKOVICKÝ ${ }^{1}$, M. CHRENKOVÁ ${ }^{2}$, P. MAKOVICKÝ ${ }^{3}$, P. FLAK ${ }^{2}$, Z. FORMELOVÁ ${ }^{2}$, V. NOVOSADOVÁ ${ }^{1}$, M. RAJSKÝ ${ }^{2}$, L. VANNUCCI ${ }^{4}$}

${ }^{1}$ Czech Centre for Phenogenomics, Division BIOCEV, Vestec, Czech Republic, ${ }^{2}$ Institute for Nutrition, National Agricultural and Food Centre, Research Institute for Animal Production Nitra, Luzianky, Slovak Republic, ${ }^{3}$ Department of Biology, Faculty of Education, Selye Janos University, Komarno, Slovak Republic, ${ }^{4}$ Laboratory of Immunotherapy, Institute of Microbiology of the Czech Academy of Sciences, Prague, Czech Republic

Received November 28, 2017

Accepted June 1, 2018

On-line September 11, 2018

\section{Summary}

The objective of this work was to compare the effect of selected feed mixtures on the duodenal morphology. One-hundred-four rats of the Wistar strain were divided to thirteen groups per eight rats. The experiment started in 35-day-old rats after birth and lasted for 32 days. The groups (A-M) were fed by commercial diet, $85 \%$ wheat and $15 \%$ oat diet, $85 \%$ wheat and $15 \%$ triticale, $85 \%$ wheat and $15 \%$ barley, $85 \%$ wheat and $15 \%$ amaranth, $85 \%$ wheat and $15 \%$ lantern, $85 \%$ wheat and $15 \%$ buckwheat, $100 \%$ wheat, $100 \%$ white lupine, $100 \%$ flock peas - variety Garden, $100 \%$ native peas - variety Garden, $100 \%$ native peas - variety Zekon or $100 \%$ extruded peas - variety Zekon diet, respectively. Samples from the duodenum were taken. The height of the villi and the depth of the crypts were measured. The tallest villi were measured in group $F$ $(474.33 \pm 114.36 \mu \mathrm{m})$ and the shortest villi were observed in group B $(294.08 \pm 88.52 \mu \mathrm{m})$. The deepest crypts were measured in group $\mathrm{K}(166.41 \pm 35.69 \mu \mathrm{m})$ and the shallowest crypts were observed in group $E(77.85 \pm 17.61 \mu \mathrm{m})$. The work documents that gluten-free and classical cereals combination can be a better choice for people who want to limit the gluten content of the diet.

\section{Key words}

Celiac disease • Gluten-free diet • Cereals • Nutrition • Villi intestinalis

\section{Corresponding author}

L. Vannucci, Laboratory of Immunotherapy, Institute of Microbiology of the Czech Academy of Sciences, Videnska 1083, 14220 Prague 4, Czech Republic. E-mail: vannucci@biomed.cas.cz

\section{Introduction}

Besides cereals like wheat, barley, the foodprocessing industry also uses some gluten-free products like amaranth, lantern, legumes, lupine and peas. They have prospective uses in human as well as animal nutrition in ecological agriculture. The main group of consumers of such products are people with celiac disease (CD), which is a life-long disorder with intolerance to gluten. Currently, people with this intolerance can only manage their symptoms by following a strict life-long gluten-free diet (Al-Bawardy et al. 2017, Shannahan and Lefler 2017). The increasing number of newly diagnosed patients has also increased demand for the above-mentioned products in the common food trade network. Otherwise gluten-free products are also often added to classical bakery products to improve the quality of the resulting products. Supplementation of gluten-free cereals to classical bread has become currently a common practice in a number of countries. Several studies have shown that there is a possibility to use many gluten-free cereals and legumes in the broader food industry (Belghith-Fendri et al. 2016, Wu et al. 2017), but currently not much is known about their effects on small bowel morphology. Part of the population want to live healthy and passing to gluten-free diet, but they are healthy. Some experts warn against these trends, but we are of the opinion that combination 
of classical gluten food with gluten-free diet is a possibility for people who want to limit the gluten in their diet. The small bowel is the most important organ of digestion and absorption, and a target for gluten adverse effects. It is obvious that various types of diets may have different effects on digestion, and long-term feeding will affects the mucosal morphology of the small bowel. Changes mainly in the villous-crypts relief, including height of villi and depth of crypts are in relation to nutrients resorption that is considered with the villi growth and crypts deepening. So therefore, the morphometric data of the small bowel can be practically and usefully used to document the nutrition effects on digestive capacity and on health. In addition, the foodprocessing industry has already been working with the hypotheses of food production on the basis of gluten-free materials, but since today it is not well known which combination is characterized by easier degradation and, possibly, by high nutritional effect. This information would be very useful for food industry. In this study, we tested the effect of selected feed mixtures of wheat, oat, triticale, barley, amaranth, lantern, buckwheat, lupine and peas on duodenal morphology. Duodenal biopsies are currently performed to achieve diagnosis and evaluation of damage from $\mathrm{CD}$ in patients. Availability of simple morphometric data addressing to different condition of mucosal health, following a specific diet, can be helpful in managing patients $\mathrm{CD}$, but also for general population. The objective of this work is to compare the height of villi and depth of crypts after ingestion of different feed mixture cereals and gluten-free cereals and legumes in the experimental rat model.

\section{Materials and Methods}

Ethics

All care and experimental procedures involving animals followed the guidelines stated in the Guide for the Care and Use of Laboratory Animals accepted by Slovak Governmental Veterinary and Food Institute. The study was approved by the Ethics Committee of the Research Institute for Animal Production Nitra in Slovak Republic (Approval number of testing equipment SK P 34004).

\section{Characteristics of the experiment}

One hundred and four rats of the Wistar strain were divided into thirteen groups ( 8 rats per group) housed in conventional cages. The design of the experiment is described also in the Table 1. After birth rats were fed by mother milk to 25 days of their life and then they were weaned and fed with standard commercial diet. Rat mothers were fed before and during pregnancy with standard commercial diet. Diet supplier (Institute of Experimental Pharmacology \& Toxicology, SAS Bratislava, Department of Toxicology and Laboratory Animals Breeding Dobra Voda). For composition of the compound feed see also Table 2. Rats were tested on the postnatal day 35 and fed the chosen diet for 32 days.

Table 1. The design of the experiment.

\begin{tabular}{ll} 
Group & \multicolumn{1}{c}{ Composition } \\
$A$ & Commercial base fed. \\
$B$ & Soft wheat $(85 \%)$ and naked oat - variety Detvan $(15 \%)$. \\
$C$ & Soft wheat $(85 \%)$ and triticale - variety Triamant $(15 \%)$. \\
$D$ & Soft wheat $(85 \%)$ and common barley $(15 \%)$. \\
$E$ & Soft wheat $(85 \%)$ and amaranth - variety Plainsman $(15 \%)$. \\
$F$ & Soft wheat $(85 \%)$ and lantern - variety Lucia $(15 \%)$. \\
$G$ & Soft wheat $(85 \%)$ and buckwheat - variety Spacinska $1(15 \%)$. \\
$H$ & Soft wheat $(100 \%)$. \\
$J$ & Lupine - variety Amiga native $(100 \%)$. \\
$K$ & Flock peas - variety Garde $(100 \%)$. \\
$L$ & Native peas - variety Garde $(100 \%)$. \\
$M$ & Native peas - variety Zekon $(100 \%)$. \\
& Extruded peas - variety Zekon $(100 \%)$.
\end{tabular}


Table 2. Composition of compound feed (in \% dry matter).

\begin{tabular}{lc} 
Component & $\begin{array}{c}\text { An amount equivalent } \\
\text { to } \mathbf{1 0} \% \mathbf{C P}\end{array}$ \\
\hline Saccharose & $10 \%$ \\
Mineral mixture & $6 \%$ \\
Vitamin mixture & $2 \%$ \\
Oil & $5 \%$ \\
Cellulose & to $4 \%$ fiber \\
Starch & to $100 \%$ \\
\hline
\end{tabular}

$\mathrm{CP}$ - crude protein.

Control group A was fed with standard commercial feed for rat and mice used for the duration of the experiment. Group B was fed a mixture of $85 \%$ soft wheat (Triticum aestivum) and $15 \%$ naked oat (Avena nuda - variety Detvan). Group C was fed a mixture of $85 \%$ soft wheat (Triticum aestivum) and 15\% triticale (Triticosecale variety - Triamant). Group D was fed a mixture of $85 \%$ soft wheat (Triticum aestivum) and $15 \%$ common barley (Hordeum vulgare - variety KM2283). Group E was fed a mixture of $85 \%$ soft wheat (Triticum aestivum) and $15 \%$ amaranth (Amarantus spp., variety Plainsman). Group F was fed a mixture of $85 \%$ soft wheat (Triticum aestivum) and $15 \%$ lantern (Medicago sativa - variety Lucia). Group $\mathrm{G}$ was fed a mixture of $85 \%$ soft wheat (Triticum aestivum) and $15 \%$ buckwheat (Fagopyrum esculentum - variety Spacinska 1). Group H was fed $100 \%$ wheat (Triticum aestivum). Group I was fed $100 \%$ white lupine (Lupinus albus native - variety Amiga native). Group J was feed $100 \%$ flock peas (Pisum sativum - variety Garden). Group K was fed $100 \%$ native peas (Pisum sativum - variety Garden). Group L was fed $100 \%$ native peas (Pisum sativum - variety Zekon) and group $M$ was fed $100 \%$ extruded peas (Pisum sativum - variety Zekon). Food and water were available to all animals ad libitum. Standard zootechnic and veterinary conditions were always maintained.

\section{Sampling}

Rats were euthanized in $\mathrm{CO}_{2}$ chamber. Samples from the small intestine were obtained by necropsy less than $30 \mathrm{~min}$ after death. One sample of the proximal duodenum (the superior duodenal flexure) was taken from each animal and fixed in $4 \%$ formalin solution for one week.

\section{Histological methods and samples evaluation}

The samples were processed by standard histological methods and embedded in paraffin blocks. 3-5 $\mu \mathrm{m}$ serial sections were cut using a microtome. The slices were placed on standard slides and stained with hematoxylin-eosin. The samples were viewed and evaluated using an Olympus Provis BX50 microscope (Olympus, Japan) equipped with Nikon camera (Nikon Digital Sight DS-Fi1, Japan). Objective assessment achieved by the measurement of the height of villi and depth of crypts was carried out using the NIS-Elements software, version 3.0 (Laboratory Imaging s.r.o., Prague, Czech Republic). In each sample, ten areas were selected, in which ten villi and ten crypts were measured. There were eight measurements for each animal making 80 measurements of height of villi and 80 measurements of depth of crypts in total.

\section{Statistical evaluation of the experiment}

All data were statistically analyzed using the following tests: basic statistical characteristics, correlations, ANOVA and MANOVA. Statistical computation was carried out using Statistix9 and IfoStat packages. Differences were declared significant at $\mathrm{p}<0.05$.

\section{Results}

As shown in Table 3, the tallest villi were measured in F group $(474.33 \pm 114.36 \mu \mathrm{m})$. Lower heights of the villi values were measured in $\mathrm{G} \quad(459.36 \pm 107.29 \mu \mathrm{m}), \quad \mathrm{E}(458.61 \pm 65.26 \mu \mathrm{m})$, C $(457.45 \pm 95.25 \mu \mathrm{m})$ groups, followed by D $(429.50 \pm$ $101.66 \mu \mathrm{m}), \mathrm{M}(421.39 \pm 71.98 \mu \mathrm{m}), \mathrm{J}(419.72 \pm 83.76 \mu \mathrm{m})$ and A $(399.29 \pm 75.77 \mu \mathrm{m})$ groups. Even shorter villi heights were measured in $\mathrm{K}(396.35 \pm 88.818 \mu \mathrm{m})$, $\mathrm{H} \quad(391.04 \pm 82.56 \mu \mathrm{m}), \quad \mathrm{L} \quad(388.72 \pm 78.40 \mu \mathrm{m}) \quad$ and I $(387.34 \pm 55.44 \mu \mathrm{m})$ groups. The shortest villi were measured in group B $(294.08 \pm 88.52 \mu \mathrm{m})$.

The deepest crypts were measured in group $\mathrm{K}$ $(166.41 \pm 35.69 \mu \mathrm{m})$. Slightly shallower crypts were measured in group $\mathrm{J}(165.25 \pm 38.19 \mu \mathrm{m})$, followed by A $(138.90 \pm 22.03 \mu \mathrm{m}), \quad \mathrm{M}(136.31 \pm 51.95 \mu \mathrm{m}), \quad$ I $\quad(123.71 \pm$ $24.21 \mu \mathrm{m}), \mathrm{L}(103.70 \pm 35.53 \mu \mathrm{m}), \mathrm{H}(103.32 \pm 23.51 \mu \mathrm{m})$ and $\mathrm{F} \quad(101.21 \pm 30.65 \mu \mathrm{m})$ groups. Very shallow crypts were measured in B $(93.37 \pm 36.57 \mu \mathrm{m})$, D $(83.03 \pm 24.85 \mu \mathrm{m}), \quad \mathrm{C} \quad(82.65 \pm 21.93 \mu \mathrm{m}) \quad$ and $\mathrm{G}(78.47 \pm 16.20 \mu \mathrm{m})$ groups. The shallowest crypts were measured in group E $(77.85 \pm 17.61 \mu \mathrm{m})$. Table 3 shows the basic statistical characteristics of villus height and crypt depth by analyzed groups and correlations between these traits in groups. Minimal average 
Table 3. Basic statistical characteristics of villus height and crypt depth with their correlations in groups.

\begin{tabular}{llllllllll}
\hline \multirow{2}{*}{ Group } & \multicolumn{9}{c}{ Villus height } \\
\cline { 2 - 7 } & Mean & SD & SEM & V \% & Mean & SD & SEM & V \% & \multirow{2}{*}{ r } \\
\hline$A$ & 399.29 & 75.77 & 8.47 & 18.98 & 138.90 & 22.03 & 2.46 & 15.86 & $0.3812^{* *}$ \\
$B$ & 294.08 & 88.52 & 9.90 & 30.10 & 93.37 & 36.57 & 4.09 & 39.17 & $0.5013^{* *}$ \\
$C$ & 457.45 & 95.25 & 10.65 & 20.82 & 82.65 & 21.93 & 2.45 & 26.54 & 0.0678 \\
$D$ & 429.50 & 101.66 & 11.37 & 23.67 & 83.03 & 24.85 & 2.78 & 29.93 & $0.3855^{* *}$ \\
$E$ & 458.61 & 65.26 & 7.30 & 14.23 & 77.85 & 17.61 & 1.97 & 22.62 & 0.0386 \\
$F$ & 474.33 & 114.36 & 12.79 & 24.11 & 101.21 & 30.65 & 3.43 & 30.28 & 0.1228 \\
$G$ & 459.36 & 107.29 & 12.00 & 23.36 & 78.47 & 16.20 & 1.81 & 20.65 & 0.2075 \\
$H$ & 391.04 & 82.56 & 9.23 & 21.11 & 103.32 & 23.51 & 2.63 & 22.75 & 0.0704 \\
$I$ & 387.34 & 55.44 & 6.20 & 14.31 & 123.71 & 24.21 & 2.71 & 19.57 & 0.0185 \\
$J$ & 419.72 & 83.76 & 9.36 & 19.96 & 165.25 & 38.19 & 4.27 & 23.11 & 0.2081 \\
$K$ & 396.35 & 88.818 & 9.93 & 22.41 & 166.41 & 35.69 & 3.99 & 21.45 & $0.2545^{*}$ \\
$L$ & 388.72 & 78.40 & 8.77 & 20.17 & 103.70 & 35.53 & 3.97 & 34.26 & -0.0299 \\
$M$ & 421.39 & 71.98 & 8.05 & 17.08 & 136.31 & 51.95 & 5.814 & 38.11 & -0.1727 \\
\hline
\end{tabular}

Mean - average, SD - standard deviation, SEM - standard error of mean, $\vee \%$ percentual variation, $r-$ correlation. $* p<0.05, * * p<0.01$.

Table 4. One-way analyses of variance of analyzed traits.

\begin{tabular}{|c|c|c|c|c|}
\hline \multirow{2}{*}{ Traits } & & Groups & Error & \multirow{2}{*}{$\mathbf{F}_{\alpha}(12,1027)$} \\
\hline & & $\mathbf{f}_{\mathrm{G}}=\mathbf{1 2}$ & $f_{e}=1027$ & \\
\hline \multirow[t]{3}{*}{ Villus height } & MS & 177903.81 & 7534.83 & $\mathrm{~F}_{0.05} ; 1.762$ \\
\hline & $\mathrm{F}$ & $23.61 * * *$ & & $\mathrm{~F}_{0.01} ; 2.202$ \\
\hline & & & & $\mathrm{F}_{0.001} ; 2.774$ \\
\hline \multirow[t]{2}{*}{ Crypt depth } & MS & 78971.89 & 943.51 & \\
\hline & $\mathrm{F}$ & $83.70 * * *$ & & \\
\hline
\end{tabular}

$* * * \mathrm{p}<0.001$.

value of villus height was found in the group B $(294 \mu \mathrm{m})$ and maximal was in the group $\mathrm{F}(474.33 \mu \mathrm{m})$. For crypt depth minimal average value was in group E $(77.85 \mu \mathrm{m})$ and maximal one in group $\mathrm{K}(166.41 \mu \mathrm{m})$. The significant or highly significant correlations between analyzed traits were obtained only for groups A, B, D and K.

Table 4 shows the ANOVA for analyzed traits. The differences between groups in both traits were highly significant.

Tukey t-test for homogenous groups shows, that there is difference between groups in both analyzed traits for $\alpha=0.05$ and $\alpha=0.01$. There is not clear significant pattern in significant difference between treatments in height of villous. Generally animals treated by soft wheat with mixture have significantly greater height of villous (except of group A and B). Group B had the smallest height of villous from all tested treatments and highest variance $(30 \%)$, but still this variance is not so big to show on error in measurement.

Furthermore there is clear influence of treatment on crypt depth. With the exception of treatment $A$, the depth is significantly smaller for all soft wheat treatments. For detailed difference see Table 5.

\section{Discussion}

The increasing incidence of diseases, including an increasing percentage of people suffering from allergies, requires special dietary regimes. There are also other diseases that have benefit from special and easily digestible diets (e.g. type 2 diabetes, Morbus Crohn, Pancreatitis diet). At present the food-production industry 
Table 5. Tukey $T$ test - homogenous groups for $a=0.05$ and $a=0.01$.

\begin{tabular}{cccccccc}
\hline & \multicolumn{2}{c}{ Villus height } & \multicolumn{5}{c}{ Crypt depth } \\
\hline \multirow{2}{*}{ Group } & Mean & $\begin{array}{c}\text { Homogenous groups, } \boldsymbol{\alpha} \\
\text { 0.05 }\end{array}$ & $\mathbf{0 . 0 1}$ & Group & Mean & $\mathbf{0 . 0 5}$ & $\mathbf{0 . 0 1}$ \\
\hline$F$ & 474.33 & $a$ & $a$ & $K$ & 166.41 & $a$ & $a$ \\
$G$ & 459.36 & $a b$ & $a b$ & $J$ & 165.25 & $a$ & $a$ \\
$E$ & 458.61 & $a b$ & $a b$ & $A$ & 138.90 & $b$ & $b$ \\
$C$ & 457.45 & $a b$ & $a b$ & $M$ & 136.31 & $b$ & $b$ \\
$D$ & 429.50 & $a b c$ & $a b c$ & $I$ & 123.71 & $b$ & $b$ \\
$M$ & 421.39 & $b c$ & $b c$ & $L$ & 103.70 & $c$ & $c$ \\
$J$ & 419.72 & $b c$ & $b c$ & $H$ & 103.32 & $c$ & $c$ \\
$A$ & 399.29 & $c$ & $c$ & $F$ & 101.21 & $c$ & $c d$ \\
$K$ & 396.35 & $c$ & $c$ & $B$ & 93.37 & $c d$ & $c d e$ \\
$H$ & 391.04 & $c$ & $c$ & $D$ & 83.03 & $d$ & $d e$ \\
$L$ & 388.72 & $c$ & $c$ & $C$ & 82.65 & $d$ & $e$ \\
$I$ & 387.34 & $c$ & $c$ & $G$ & 78.47 & $d$ & $e$ \\
$B$ & 294.08 & $d$ & $d$ & $E$ & 77.85 & $d$ & $e$ \\
\hline
\end{tabular}

The treatments with the different letters are significantly different.

is focused on exploring the possibilities of producing food with a better content of energetically utilizable components (Schönfeldt and Gibson 2010). A number of additives are being tested, including some gluten-free cereals and legumes used in the form of additives in food products. They are also commonly used in gluten-free diets, but their effects on small bowel morphology are not well known. This is very important to know, because decreased small bowel resorption is a concomitant phenomenon of several diseases and common postoperative consequence. On the other hand, it is also well known that European populations are today affected by several civilization diseases, including overweight and obesity (Doak et al. 2012, Honzikova and Zavodna 2016). Thus, additional knowledge about the effects of individual food additives on the duodenal morphology is necessary and may result in practical output for dietetic indication and preparation of better nutritional products. Some animal models for celiac disease were established and the effects of various diet have been investigated (Costes et al. 2015, Ju et al. 2015). Moreover, not much is known with regards to the best supplement options as food additive for healthy people. Consequently, in our experiment we compared the influence of several feed mixture additives on the duodenal morphology. Using an animal model, we have shown some rather impressive changes in villus structure on different diets given over only a period of just a month. This has some intriguing implications, even for adaptation changes in humans on different diets, particularly in the area of food faddism, never mind celiac disease. The histological findings shows normal views and in the representative Figure 1 there are some examples of normal small bowels. On the other hand the results of measurements show some differences between experimental groups. The results of morphometry show that lantern, buckwheat, amaranth and triticale have positive effects on the height of villi compared with commercial based feed. On the other hand oats have a negative effect on the height of villi. Oats have been studied for several decades and there are different conclusions as to their addition to gluten-free diet. European legislation specifies the use of oats for gluten-free diet. Oats contained in a food presented as "gluten-free" or "very low gluten" must have been specially produced, prepared and/or processed in a way to avoid contamination by wheat, rye, barley, or their crossbred varieties and the gluten content of such oats cannot exceed $20 \mathrm{mg} / \mathrm{kg}$. On the other hand, it was suggested that it may only be certain strains of oats which could produce a toxic response to people with celiac disease (Gimenez et al. 2017). A long-term dietary intake of oats or oat bran could benefit inflammatory bowel disorders, but the protective effect from colorectal adenoma and cancer incidence has not yet been 


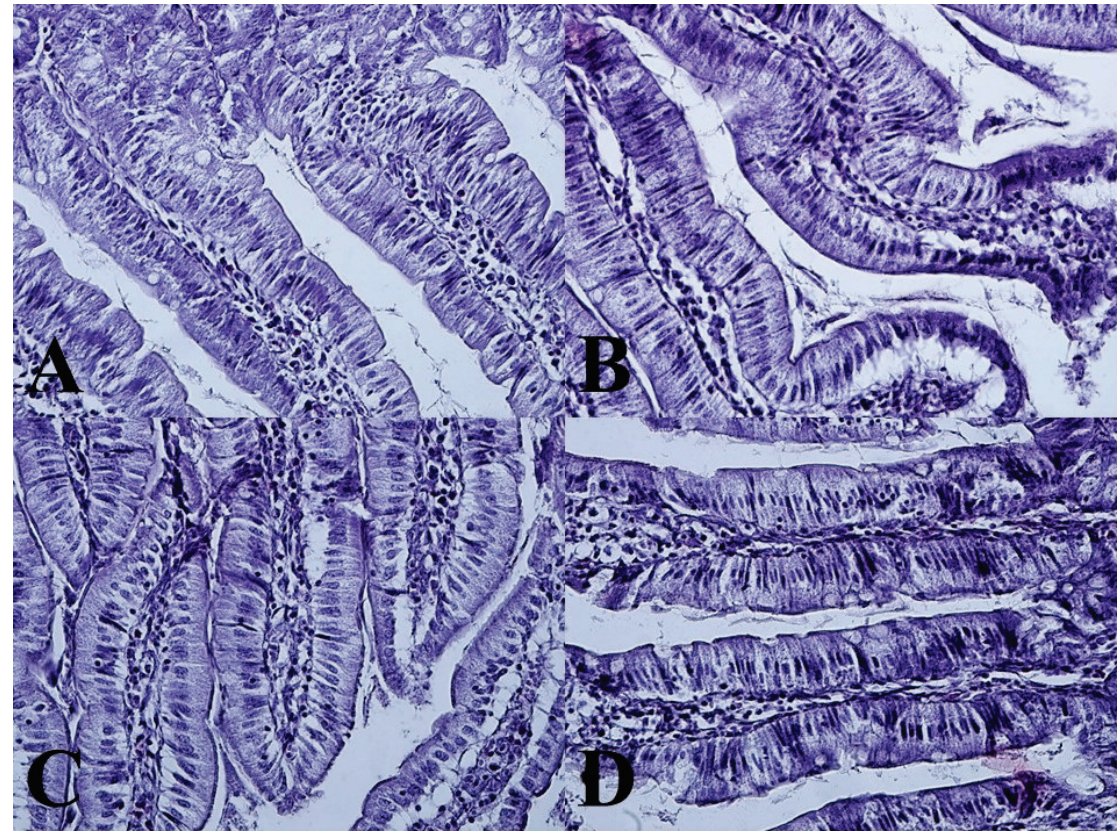

Fig. 1. Representative aspects of duodenal mucosa from differently fed rats. A. Commercial base feed. Hematoxylin-eosin: 400x. B. Soft wheat $(85 \%)$ and amaranth - variety Plainsman (15\%). Hematoxylin-eosin: 400x. C. Flock peas - variety Garde (100\%). Hematoxylin-eosin: 400x. D. Native peas - variety Zekon (100 \%). Hematoxylin-eosin: 400x.

convincingly shown (Thies et al. 2014). Our data shows that some cereals have significantly better effects on villous relief compared to commercial based feed. Similar observations are made with legumes and commercial based feed comparisons. Therefore, starting from the working hypothesis of the positive effect of basic feed mixture with additives we can confirm that there are differences in the height of villi and depth of crypts. Our results show that addition of peas to the diet gives better results, compared to commercial based feed, or only wheat feed. From our point of view, peas are a suitable alternative of nutrition or a component of nutrition in diets and our results show that there are some differences between different peas groups. In previous work, no differences were documented in chemical composition and meat quality among experimental pig groups fed peas and peas can be included in diets at $15 \%$ for growingfinishing pigs, $30 \%$ for the growing phase and $30 \%$ during the finishing phase (Chrastinova et al. 2005). Diets containing peas need to be fortified with synthetic amino acids to balance the composition of the diet. In addition, pea components implementation in the foodprocessing industry can bring diversity to the diet of people, including celiac disease diet. Buckwheat and amaranth are already used in practice for such purposes and their enhanced final nutritional quality was documented (Gambus et al. 2009, Sebestyen et al. 2013). It is mentioned that their nutritional value is interesting mainly because of significantly higher levels of protein, fat, fiber and minerals than the control bread (AlvarezJubete et al. 2009). Today they are globally used in development of functional gluten-free foods as bread, cookies, pasta, noodles and beer (Gimenez-Bastida et al. 2016). Our results on experimental rats show the positive effects on the villi heights and depth of crypts of different feed mixtures with gluten-free cereals and legumes. Legumes and some cereals are suitable for gluten-free diet, because they have a content of prolamin less than $4 \%$ (Mlynekova et al. 2014). Positive effects of legumes suggest that cellulose fiber may have played a significant role in small bowel villous architecture, which was confirmed also by one well written earlier study (Dirk and Freeman 1987). Height of the villi and depth of the crypts are the important parameters of the small bowel morphology. They are dynamically changing and adapting to current nutrition and their parameters are important signs of small bowel absorption possibilities. They were subject of several works dealing with diseases (Rallabhandi 2012), food restriction (Tumova et al. 2016), different short-term dietary regimes (Pauwels 2011), but also for maintaining certain principles of healthy nutrition (Martinkova et al. 2000), or genetically modified products (Ibrahim and Okasha 2016). Larger villi relief enables greater contact with chyme and therefore greater absorption of nutrients. The greater number of blood and lymphatic capillaries in these villi enables the better transport of the absorbed compounds through the blood. It is well known, that many people decide to adhere to gluten-free diet, even if they do not have any health problems with gluten. For example, in the United States, about one-third of people report trying to avoid gluten (Jargon 2014). These facts are supported 
by many myths about gluten-free diet. It is primarily about slimming, healthy lifestyle, or detoxification and conviction of general gluten harm (Koning 2015, Nash and Slutzky 2014). The work of Reilly (2016) documents that following a gluten-free diet can be at the end harmful for healthy people. On the other hand some studies have shown that non-celiac autoimmune diseases can partially respond to gluten-free diet (Lerner et al. 2017). In fact the mechanisms by which gluten-free diet can effects, or alleviate non-celiac autoimmune diseases initiation, or progression are today not clear. Every article bringing facts is valuable, and should not nourish false hope in people. Strict gluten-free diet is designed for special dietary purposes; it is not about fashion and cannot be recommended as a miraculous diet with the power to cure everyone. It should also be clear that it is not a guarantee of a better mood, or happiness. Here dietitians play a pivotal role in the education, follow-up and navigation of the special diets for individual disease (Lerner and Torsten 2017). The work of Coattrenec et al. (2015) states there is no strong evidence for a strict indication to a gluten-free diet in endocrinologic, psychiatric, and rheumatologic diseases, or to improve performance in elite sports.

\section{Conclusions}

This work documents that the combination of gluten-free cereals and classical cereals can be a better choice for people who want to limit the gluten intake in the body, but also to maintain adequate mucosal morphology of the intestine for a valid digestive function.

\section{Conflict of Interest}

There is no conflict of interest.

\section{Acknowledgements}

Supported by RVO 61388971, by Slovak Research and Development Agency under the contract No. APVV-150477\&\#8220 and by BIOCEV-CZ.1.05/1.1.00/02.0109. We would like to thank Nicole Chambers, Ph. D., for her English editorial assistance with this manuscript.

\section{References}

AL-BAWARDY B, CODIPILLY DC, RUBIO-TAPIA A, BRUINING DH, HANSEL SL, MURRAY JA: Celiac disease: a clinical review. Abdom Radiol 42: 351-360, 2017.

ALVAREZ-JUBETE L, ARENDT EK, GALLAGHER E: Nutritive value and chemical composition of pseudocereals as gluten-free ingredients. Int J Food Sci Nutr 60: 240-257, 2009.

BELGHITH-FENDRI L, CHAARI F, KALLEL F, ZOUARI-ELLOUZI S, GHORBEL R, BESBES S, ELLOUZCHAABOUNI S, GHRIBI-AYDI D: Pea and broad bean pods as a natural source of dietary fiber: the impact on texture and sensory properties of cake. J Food Sci 81: 2360-2366, 2016.

CHRASTINOVA L, CHRENKOVA M, FLAK P, LAHUCKY R, FORMELOVA Z, CERESNAKOVA Z, MAKOVICKY P: The effect of including pea in diets for growing-finishing pigs on performance and meat quality. Arch Zootech 8: 91-96, 2005.

COATTRENEC Y, HARR T, PICHARD C, NENDAZ M: Benefits of gluten-free diet: myth or reality? Rev Med Suisse 11: 490, 2015.

COSTES LM, MERESSE B, CERF-BENSUSSAN N, SAMSOM JN: The role of animal models in unravelling therapeutic targets in coeliac disease. Best Pract Res Clin Gastroenterol 29: 437-450, 2015.

DIRKS P, FREEMAN HJ: Effects of differing purified cellulose, pectin and hemicellulose fiber diets on mucosal morphology in the rat small and large intestine. Clin Invest Med 10: 32-38, 1987.

DOAK CM, WIJNHOVEN TM, SCHOKKER DF, VISSCHER TL, SEIDELL JC: Age standardization in mapping adult overweight and obesity trends in the WHO European region. Obes Rev 13: 174-191, 2012.

GAMBUS H, GAMBUS F, PASTUSZKA D, WRONA P, ZIOBRO R, SABAT R, MICKOWSKA B, NOWOTNA A, SIKORA M: Quality of gluten-free supplemented cakes and biscuits. Int J Food Sci Nutr 60: 31-50, 2009.

GIMENEZ MJ, REAL A, GARCIA-MOLINA MD, SOUSA C, BARRO F: Characterization of celiac disease related oat proteins: based for the development of high quality oat varieties suitable for celiac patients. Sci Rep 17: $42588,2017$.

GIMENEZ-BASTIDA JA, PISKULA M, ZIELINSKI H: Recent advances in development of gluten-free buckwheat products. Trends Food Sci Technol 44: 58-65, 2016. 
HONZIKOVA N, ZAVODNA E: Baroreflex sensitivity in children and adolescent: physiology, hypertension, obesity, diabetes mellitus. Physiol Res 65: 879-889, 2016.

IBRAHIM MA, OKASHA EF: Effect of genetically modified corn on the jejunal mucosa of adult male albino rat. Exp Toxicol Pathol 68: 579-588, 2016.

JARGON J: The gluten-free craze: is it healthy? Wall Street J 6: 22, 2014.

JU JM, MARIETTA EV, MURRAY JA: Generating transgenic mouse models for studying celiac disease. Methods Mol Biol 1326: 23-33, 2015.

KONING F: Adverse effects of wheat gluten. Ann Nutr Metab 67: 8-14, 2015.

LERNER A, TORSTEN M: Gluten-free diet - tough alley in torrid time. Int J Celiac Dis 5: 50-55, 2017.

LERNER A, SHOENFELD Y, MATTHIAS T: Adverse effects of gluten ingestion and advantages of gluten withdrawal in nonceliac autoimmune disease. Nutr Rev 75: 1046-1058, 2017.

MARTINKOVA A, LENDHARDT L, MOZES S: Effect of neonatal MSG treatment on day-night alkaline phosphatase activity in the rat duodenum. Physiol Res 49: 339-345, 2000.

MLYNEKOVA Z, CHRENKOVA M, FORMELOVA Z: Cereals and legumes in nutrition of people with celiac disease. Int J Celiac Dis 2: 105-109, 2014.

NASH DT, SLUTZKY AR: Gluten sensitivity: new epidemic or new myth? Proc (Bayl Univ Med Cent) 27: 377-378, 2014.

PAUWELS EK: The protective effects of the Mediterranean diet: focus on cancer and cardiovascular risk. Med Princ Pract 20: 103-111, 2011.

RALLABHANDI P: Gluten and celiac disease - an immunological perspective. J AOAC Int 95: 349-362, 2012.

REILLY NR: The gluten-free diet: recognizing fact, fiction, and fad. J Pediatr 175: 206-210, 2016.

SCHÖNFELDT HC, GIBSON N: Food composition data in health communication. Eur J Clin Nutr 64: 28-33, 2010.

SEBESTYEN A, KISS Z, VECSERI-HEGYES B, KUN-FARKAS G, HOSCHKE A: Experiences with laboratory and pilot plant preparation of Millet and Buckwheat beer. Acta Aliment 42: 81-89, 2013.

SHANNAHAN S, LEFFLER DA: Diagnosis and updates in celiac disease. Gastrointest Endos Clin North Am 27: 79-92, 2017.

THIES F, MASSON LF, BOFFETTA P, KRIS-ETHERTON P: Oats and bowel disease: a systematic literature review. Brit J Nutr 112: S31-S43, 2014.

TUMOVA E, VOLEK Z, CHODOVA D, HARTLOVA H, MAKOVICKY P, SVOBODOVA J, EBEID TA, UHLIROVA L: The effect of 1-week feed restriction on performance, digestibility of nutrients and digestive system development in the growing rabbit. Animal 10: 1-9, 2016.

WU T, TAYLOR C, NEBL T, NG K, BENNETT LE: Effects of chemical composition and baking on in vitro digestibility of proteins in breads made from selected gluten-containing and gluten-free flours. Food Chem 233: 514-524, 2017. 